\title{
HISTOPATHOLOGICAL PROFILE OF ABNORMAL UTERINE BLEEDING- A TWO-YEAR SINGLE- INSTITUTIONAL STUDY
}

\author{
Anbu Lenin Kulandaivel1, Kumudhini Priya Gunasekaran²
}

${ }_{1}^{1}$ Assistant Professor, Department of Pathology, Vinayaka Mission's Kirupananda Variyar Medical College and Hospital, Salem, Tamilnadu, India.

${ }^{2}$ Consultant Pathologist, Department of Pathology, Shanmugha Hospitals and Salem Cancer Institute, Salem, Tamilnadu, India.

\section{ABSTRACT}

\section{BACKGROUND}

Abnormal uterine bleeding is the leading cause for the Gynaecologist's referral and it accounts for two-thirds of all Hysterectomies. Various causes including structural and non-structural can result in abnormal uterine bleeding. Abnormal uterine bleeding can result in significant morbidity and can interfere with personal and social well-being.

The aim of this study is to evaluate the structural and non-structural causes associated with abnormal uterine bleeding and to study the endometrial patterns among hysterectomy specimens without structural abnormality.

\section{MATERIALS AND METHODS}

Hysterectomy specimens of all the patients who presented with complaints of Abnormal Uterine Bleeding were selected and detailed histopathological analysis done. Findings were correlated with clinical symptoms and available investigations. Pregnancy related complications and cases of cervical carcinomas were not included in the study.

Statistical Analysis Used- The data obtained were analysed using SPSS Software Version 17.

Settings and Design- This is a hospital-based descriptive study on 408 hysterectomy specimens conducted at Shanmugha Hospitals and Salem Cancer Institute, Salem, Tamilnadu.

\section{RESULTS}

A total of 408 hysterectomy specimens were included in the study. Age group of the patients included in the study ranged from 20 to 80 years with $245(60.04 \%)$ patients between 41 and 50 years. Of 408 specimens, $276(67.64 \%)$ had structural abnormality. Majority in the study group had Leiomyoma, which accounted for 164 (40.19\%) cases followed by abnormal uterine bleeding with endometrium in proliferative phase accounting for 84 (20.58\%) cases. Remaining histopathological profiles included 24 (5.88\%) secretory endometrium, 10 (2.45\%) endometrial atrophy, $05(1.22 \%)$ disordered proliferative endometrium, 57 (13.97\%) adenomyosis, $35(8.57 \%)$ endometrial polyp, $7(1.71 \%)$ endometrial hyperplasia, $3(0.7 \%)$ endocervical polyp, $2(0.49 \%)$ granulomatous endometritis and 17 (4.16\%) endometrial carcinomas.

\section{CONCLUSION}

Various structural and non-structural causes are associated with abnormal uterine bleeding. Most common cause associated with abnormal uterine bleeding in our study and institution is Leiomyoma which constitutes for $40.19 \%$ with least being Granulomatous Endometritis (0.49\%).

\section{KEY WORDS}

Abnormal Uterine Bleeding, Hysterectomy, Leiomyoma, Polyp, Adenomyosis, Endometrial Carcinoma.

HOW TO CITE THIS ARTICLE: Kulandaivel AL, Gunasekaran KP. Histopathological profile of abnormal uterine bleeding- a twoyear single-institutional study. J. Evolution Med. Dent. Sci. 2018;7(29):3300-3303, DOI: 10.14260/jemds/2018/743

\section{BACKGROUND}

Cyclical changes which occurs in endometrium is balanced by complex interplay of endogenous steroids and various other factors.[1] Abnormal uterine bleeding is defined as a bleeding pattern that differs either in volume, frequency, duration or in combination of all from pattern that is observed during normal menstrual cycle.[2] Abnormal uterine bleeding is one of the common cause for hospital visit among women of reproductive age group.[3] Abnormal uterine bleeding is associated with various causes, which includes ovarian dysfunction, endometrial causes, coagulopathies, systemic

'Financial or Other Competing Interest': None.

Submission 05-06-2018, Peer Review 29-06-2018,

Acceptance 05-07-2018, Published 16-07-2018.

Corresponding Author:

Anbu Lenin Kulandaivel,

\#24, Gandhi Road,

S5, Visalakshi Apartments

Salem-636007, Tamilnadu, India.

E-mail: dranbulenin@gmail.com

DOI: $10.14260 /$ jemds $/ 2018 / 743$ (c) $($ ) $(-)$ illness, endometrial/ endocervical polyps, adenomyosis, leiomyomas, iatrogenic, endometrial hyperplasias and carcinomas.

This study was done to evaluate various causes associated with abnormal uterine bleeding and to study the endometrial pattern among specimens with no structural abnormality.

\section{MATERIALS AND METHODS}

This is a two years hospital-based single-institutional descriptive study conducted at Shanmugha Hospitals and Salem Cancer Institute, Salem, Tamilnadu. Ethical Committee approval was taken prior to the study. 408 hysterectomy specimens of patients who were clinically diagnosed as abnormal uterine bleeding were selected for the study. Pregnancy related complications and cases of cervical carcinomas were not included in the study. Detailed clinical history and various available investigations including haematological profile, ultrasonography and thyroid profiles were collected. All the received hysterectomy specimens 
were fixed in $10 \%$ Formalin, processed and $4-5 \mathrm{u}$ thickness sections were made and stained with Haematoxylin and Eosin stain. Detailed histopathological examination was done independently by two pathologists and results were analysed using SSPS Software Version 17.

\section{RESULTS}

A total of 408 hysterectomy specimens were included in the study. Age group of the patients in the study ranged from 20 80 years with $60.04 \%$ of patients between $41-50$ years and $0.7 \%$ of patients between 71 - 80 years. Perimenopausal women were found to be the leading cause for abnormal uterine bleeding constituting about $60.04 \%$. Among 408 hysterectomy specimens, 276 (67.64\%) had structural abnormality with remaining being non-structural. 164 (40.19\%) cases had Leiomyomas with maximum being multiple. There were 57 (13.97\%) adenomyosis, 35 (8.57\%) endometrial polyp, $3(0.7 \%)$ endocervical polyp and 17 (4.16\%) endometrial carcinomas. Of 35 endometrial polyps, 7 (20\%) were leiomyomatous polyp. 8 (1.96\%) had leiomyoma and adenomyosis, $4(0.98 \%)$ had leiomyoma and endometrial polyp, $3(0.73 \%)$ had adenomyosis and endometrial polyp and $1(0.24 \%)$ had adenomyosis and endocervical polyp. 84 (20.58\%) had abnormal uterine bleeding with endometrium in proliferative phase, 24 (5.88\%) were secretory endometrium, $10(2.45 \%)$ had endometrial atrophy, 05 $(1.22 \%)$ showed disordered proliferative endometrium with $7(1.71 \%)$ cases of endometrial hyperplasia and $2(0.49 \%)$ granulomatous endometritis. All the cases of Endometrial hyperplasia were simple without atypia. Among perimenopausal women, there were 114 cases of leiomyoma which constitutes for $69.51 \%$ of total leiomyomas and $46.53 \%$ of perimenopausal bleeding. All the causes for abnormal uterine bleeding (except endometrial carcinomas and endometrial atrophy) were maximum among perimenopausal age group which includes $61.90 \%$ of proliferative endometrium, $45.83 \%$ of secretory endometrium, $64.91 \%$ of adenomyosis, $55.26 \%$ of polyps and $42.85 \%$ of endometrial hyperplasia. Endometrial carcinomas were most common among post-menopausal age group constituting for about $76.47 \%$ of endometrial carcinomas. 10 cases $(58.82 \%)$ of endometrial carcinomas were classified as endometrioid type after histopathological examination.

\begin{tabular}{|c|c|c|c|c|c|c|c|}
\hline $\begin{array}{l}\text { Histopathological } \\
\text { Finding }\end{array}$ & \begin{tabular}{|c|}
$20-$ \\
$30 Y$
\end{tabular} & \begin{tabular}{|c|}
$31-$ \\
$40 Y$
\end{tabular} & $\begin{array}{l}41- \\
50 Y\end{array}$ & \begin{tabular}{|l|}
$51-$ \\
$60 Y$
\end{tabular} & $\begin{array}{l}61- \\
70 Y\end{array}$ & \begin{tabular}{|l|}
$71-$ \\
$80 Y$
\end{tabular} & Total \\
\hline $\begin{array}{c}\text { Proliferative } \\
\text { Endometrium }\end{array}$ & 02 & 26 & 52 & 04 & 00 & 00 & $\begin{array}{c}84 \\
{[20.58 \%]}\end{array}$ \\
\hline $\begin{array}{r}\text { Sec } \\
\text { Endo }\end{array}$ & 01 & 11 & 11 & 01 & 00 & 00 & \begin{tabular}{|c|}
24 \\
{$[5.88 \%]$}
\end{tabular} \\
\hline $\begin{array}{r}\text { Atro } \\
\text { Endom }\end{array}$ & 00 & 00 & 02 & 06 & 02 & 00 & $\begin{array}{c}10 \\
{[2.45 \%]}\end{array}$ \\
\hline $\begin{array}{c}\text { Disorderly } \\
\text { Proliferative } \\
\text { Endometrium }\end{array}$ & 00 & 00 & 02 & 02 & 01 & 00 & $\begin{array}{c}05 \\
{[1.22 \%]}\end{array}$ \\
\hline Leiomyoma & 02 & 35 & 114 & 13 & 00 & 00 & $\begin{array}{c}164 \\
{[40.19 \%]}\end{array}$ \\
\hline Adenomyosis & 00 & 17 & 37 & 03 & 00 & 00 & \begin{tabular}{|c|}
57 \\
{$[13.97 \%]$}
\end{tabular} \\
\hline
\end{tabular}

\begin{tabular}{|c|c|c|c|c|c|c|c|}
\hline $\begin{array}{c}\text { Endometrial and } \\
\text { Endocervical } \\
\text { Polyp }\end{array}$ & 00 & 10 & 21 & 03 & 04 & 00 & $\begin{array}{c}38 \\
{[9.31 \%]}\end{array}$ \\
\hline $\begin{array}{l}\text { Endom } \\
\text { Hyper! }\end{array}$ & 00 & 01 & 03 & 03 & 00 & 00 & $\begin{array}{c}07 \\
{[1.71 \%]}\end{array}$ \\
\hline $\begin{array}{r}\text { Endom } \\
\text { Carcin }\end{array}$ & 00 & 01 & 03 & 05 & 05 & 03 & $\begin{array}{c}17 \\
{[4.16 \%]}\end{array}$ \\
\hline $\begin{array}{l}\text { Granulomatous } \\
\text { Endometritis }\end{array}$ & 00 & 01 & 00 & 00 & 01 & 00 & \begin{tabular}{|c|}
02 \\
{$[0.49 \%]$}
\end{tabular} \\
\hline Total & 05 & 102 & 245 & 40 & 13 & 03 & 408 \\
\hline \multicolumn{8}{|c|}{$\begin{array}{l}\text { Table 1. Age-Wise distribution of all the Cases based on } \\
\text { Histopathological Diagnosis. [Y-Years, Number of Cases } \\
\text { against each category are tabulated along with } \\
\text { percentage calculation of Total Number of Cases] }\end{array}$} \\
\hline
\end{tabular}
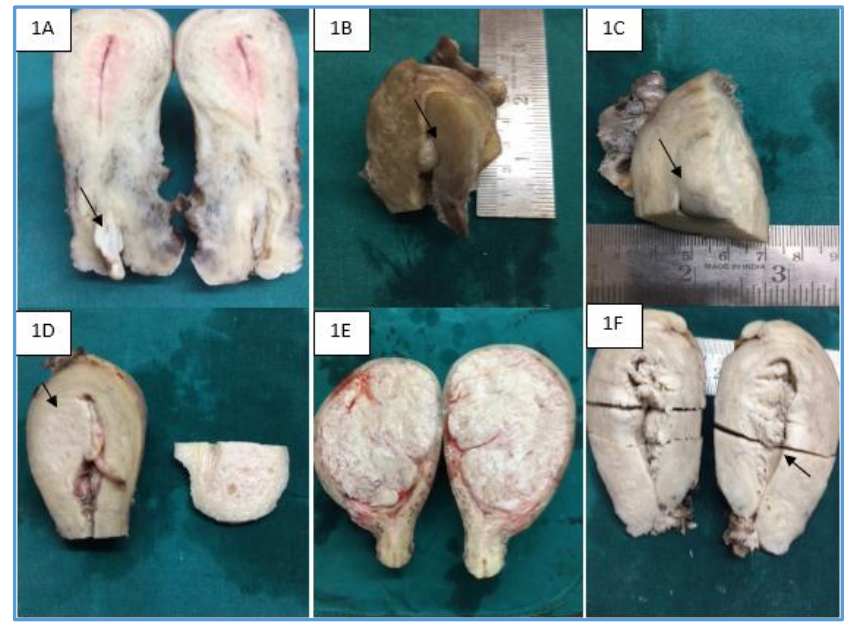

Figure 1 [1A-1F]. 1A. Endocervical Polyp, 1B. Endometrial Polyp, 1C. Leiomyomatous Polyp, 1D. Adenomyosis with Endometrial Polyp, 1E. Intramural Leiomyoma, 1F.Endometrial Carcinoma with Friable growth filling entire Endometrial Cavity

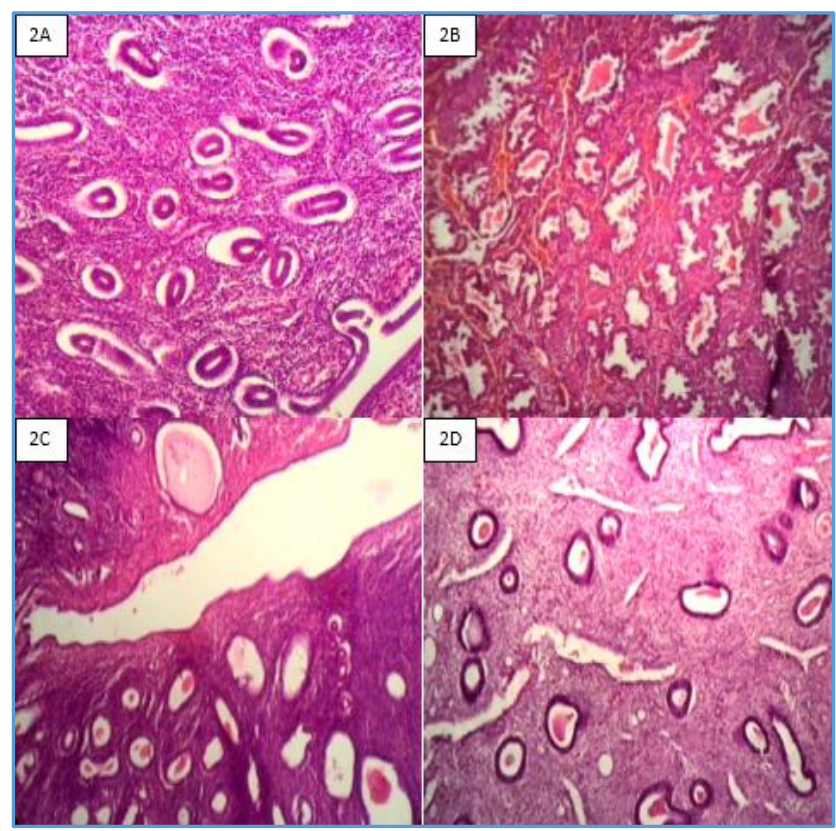

Figure 2 [2A-2D]. 2A. Proliferative Endometrium, $2 B$. Secretory Endometrium, 2C. Atrophic Endometrium, 2D. Endometrial Polyp [H and E Stain, 10X] 


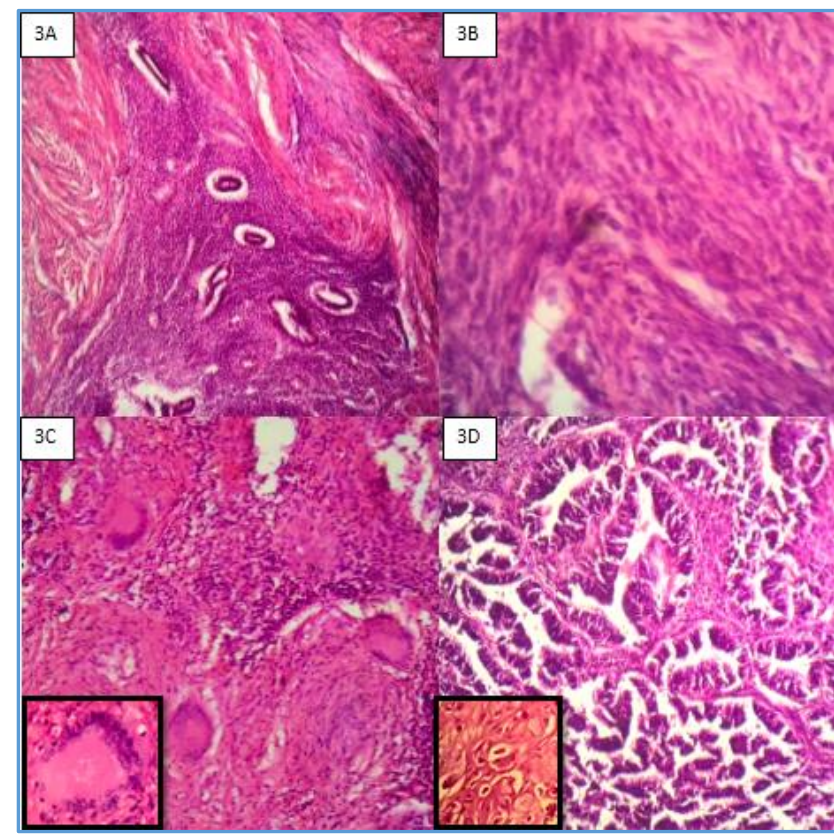

Figure 3 [3A-3D]. 3A. Adenomyosis, 3B. Leiomyoma, 3C. Granulomatous Endometritis (Inset- Langhans Giant Cell), 3D. Endometrial Adenocarcinoma- Endometrioid TypeGrade II (Inset-Squamous Morule) [H and E Stain, 10X]

\section{DISCUSSION}

Abnormal uterine bleeding is one among most important clinical entity, which affects $14-25 \%$ of women of reproductive age ${ }^{[4,5]}$ with significant impact on physical, social, emotional and material quality of life.[6] The most common aetiologies associated with abnormal uterine bleeding are leiomyomas, endometrial polyps, adenomyosis, anovulation, disorders of haemostasis and neoplasia. ${ }^{[7,8]}$ In this study, $60.04 \%$ of patients were between $41-50$ years (perimenopausal). This is comparable to study conducted by Anjali Singh et al[9] and Dadhania et al.[10] The relationship between abnormal uterine bleeding and leiomyomas remains unclear. Various causative mechanism includes alteration in plasminogen modulators, increased level of matrix metalloproteinases, alteration in vasoactive substances and impact on angiogenesis. Most common cause associated with abnormal uterine bleeding in this study is Leiomyoma (40.19\%). This is similar to study conducted by Gorla P et al[11] and Bolde SA et al.[12] The contribution of polyps to abnormal uterine bleeding is widely accepted.[13] According to Dreisler E et al[14] and Preutthipan S et al,[15] contribution of polyps to abnormal uterine bleeding ranges from $3.7 \%$ $65 \%$. In our study $8.57 \%$ were endometrial polyp, of which $20 \%$ were leiomyomatous polyp. According to Usha GD et al,[16] 9.4\% of cases were adenomyosis. In this study, 13.97\% were adenomyosis. This variation may be due to more number of cases in our study. Among non-structural causes, maximum number of cases $(20.58 \%)$ had abnormal uterine bleeding with endometrium in proliferative phase followed by secretory endometrium $(5.88 \%)$. This is comparable to study conducted by Usha GD et al. In our study, $1.71 \%$ were endometrial hyperplasia which is comparable to study conducted by Shrestha et al. $4.16 \%$ of cases were endometrial carcinomas and $76.47 \%$ of endometrial carcinomas were among postmenopausal women, which was similar to study conducted by Dangal G et al.

\section{CONCLUSION}

According to our study, which was conducted among 408 hysterectomy specimens, abnormal uterine bleeding was found most commonly among perimenopausal women and leiomyoma was the leading cause of abnormal uterine bleeding. Endometrial carcinomas occur predominantly among postmenopausal women. Among non-structural causes, predominant pattern was abnormal uterine bleeding with endometrium in proliferative phase followed by secretory pattern. As there is increased incidence of endometrial carcinomas among postmenopausal women, all the postmenopausal women presenting with abnormal uterine bleeding should be evaluated thoroughly with additional caution.

\section{REFERENCES}

[1] Avantika G, Asmita MR, Usha M, et al. Evaluation and histopathological correlation of abnormal uterine bleeding in perimenopausal women. Int J Biomed Advanced Res 2013;4(8):509-13.

[2] Al-Neaimy WMT, Ahmed MT, Al-Jawadi SI. Histopathological interpretation of abnormal uterine bleeding after the age of 40 years. Iraqi Postgrad Med J 2010;9(3):274-82.

[3] Sarwar A, ul Haque A. Types and frequencies of pathologies in endometrial curettings of abnormal uterine bleeding. International Journal of Pathology 2005;3(2):65-70.

[4] Fraser IS, Langham S, Uhl-Hochgraeber K. Healthrelated quality of life and economic burden of abnormal uterine bleeding. Expert Rev Obstet Gynecol 2009;4(2):179-89.

[5] Shapley M, Jordan K, Croft PR. An epidemiological survey of symptoms of menstrual loss in the community. Br J Gen Pract 2004;54(502):359-63.

[6] NICE. Clinical Guidelines 44; Heavy menstrual bleeding 2007. National Institute of Health and Clinical Excellence (NICE). http://www.nice.org.uk/nice media/pdf/CG44Full Guideline.pdf.

[7] Munro MG, Critchley HO, Broder MS, et al. FIGO classification system (PALM-COEIN) for causes of abnormal uterine bleeding in non-gravid women of reproductive age. Int J Gynaecol Obstet 2011;113(1):313.

[8] Tsai MC, Goldstein SR. Office diagnosis and management of abnormal uterine bleeding. Clin Obstet Gynecol 2012;55(3):635-50.

[9] Singh A, Singh S, Mathur V, Singh K, et al. Transvaginalsonography in DUB and correlation with histopathology. Journal of Obstetrics and Gynaecology of India 2001;51(6):116-9.

[10] Dadhania B, Dhruva G, Agravat A, et al. Histopathological study of endometrium in dysfunctional uterine bleeding. Int $\mathrm{J}$ Res Med 2013;2(1):20-4.

[11] Gorla P, Sanapala S, Devi E, et al. Histopathology of endometrium in abnormal uterine bleeding, in correlation with thyroid profile and ultrasonography finding. Int J Res Med Sci 2016;4(5):1463-9.

[12] Bolde SA, Pudale SS, Pandit GA, et al. Histopathological study of endometrium in cases of abnormal uterine bleeding. Int J Res Med Sci 2014;2(4):1378-81. 


\section{Jemds.com}

[13] Lieng M, Istre 0, Sandvik L, et al. Prevalence, 1-year regression rate, and clinical significance of asymptomatic endometrial polyps: cross-sectional study. J Minim Invasive Gynecol 2009;16(4):465-71.

[14] Dreisler E, Stampe Sorensen S, et al. Prevalence of endometrial polyps and abnormal uterine bleeding in a Danish population aged 20-74 years. Ultrasound Obstet Gynecol 2009;33(1):102-8.

\section{Original Research Article}

[15] Preutthipan S, Herabutya Y. Hysteroscopic polypectomy in 240 premenopausal and postmenopausal women. Fertil Steril 2005;83(3):7059.

[16] Usha GD, Doddamani GB, Geetanjali K, et al. Clinicopathological correlation of endometrium in abnormal uterine bleeding. Sch J App Med Sci 2014;2(1A):46-9. 